\title{
A Needs-Assessment Process for Designing Geospatial Data Management Systems within Federal Agencies
}

\author{
JORDAN W. SMITH, WILLIAM S. SLOCUMB, CHARLYNNE SMITH, \\ and JASON MATNEY \\ North Carolina State University, Raleigh, North Carolina, USA
}

\begin{abstract}
Many federal agencies face challenges with designing geospatial data management systems. This paper presents and documents a needs-assessment process that can be employed to prioritize agencies' geospatial information needs; identify agencies' capacity to manage a centralized geodatabase; determine agencies' capacity to deliver Web-mapping services to the public; and identify barriers, such as data security and limited financial resources, that constrain agencies' ability to design and manage a geospatial data management system. The paper details the needs-assessment process and documents its application to the National Park Service (NPS) Conservation and Outdoor Recreation (COR) Branch programs. The NPS COR Branch is comprised of nine disparate programs, such as the National Trails System and the Rivers, Trails, and Conservation Assistance program, each of which has specific geospatial data management and delivery needs. The needs-assessment process, tested through its application to the NPS COR Branch programs, provides a comprehensive and logical workflow for system developers and administrators to use as they create or refine geospatial data management systems.
\end{abstract}

KEYWORDS enterprise geodatabases, database design, federal agencies, web-based mapping services, needs assessment

\section{INTRODUCTION}

Federal agencies face numerous challenges when designing geospatial data management systems. Frequently, geospatial data management systems have

\footnotetext{
(C) Jordan W. Smith, William S. Slocumb, Charlynne Smith, and Jason Matney

Address correspondence to Dr. Jordan W. Smith, Center for Geospatial Analytics, North Carolina State University, CB 7106, 5112 Jordan Hall, Raleigh, NC 27695. E-mail: takugler@umn. edu
} 
been constructed internally by agency personnel tasked with addressing the needs of a specific program or initiative. This process results in noncompatible geospatial data "silos" or "stovepipes" (Goodchild et al. 1999). In response, federal agencies in the United States have repeatedly tried to implement standards to procure, store, and deliver geospatial data with the ultimate goal being an interoperable network of geospatial data management systems (National Research Council 1993). Until standardization efforts are widely adopted and implemented, however, individual federal agencies could benefit from tools and workflows that allow them to manage and deliver their geospatial data in the most efficient manner possible. This paper presents a needs-assessment process designed to

1. Prioritize agencies' geospatial information needs

2. Identify agencies' capacity to manage a centralized geodatabase

3. Determine agencies' capacity to deliver Web-mapping services to the public

4. Identify barriers, such as data security and limited financial resources, that constrain agencies' ability to design and manage a geospatial data management system.

The paper also presents a case-study application of the process to programs within the National Park Service (NPS) Conservation and Outdoor Recreation (COR) Branch. The needs-assessment process provides a comprehensive and logical workflow for system developers and administrators to use as they create or refine geospatial data management systems.

\section{Challenges of Designing Geospatial Data Management Systems within Federal Agencies}

Throughout their history, federal agencies in the United States have faced numerous challenges in managing geospatial information (Wood and Fels 1992). In their description of the history of geospatial information management and sharing, Goodchild, Fu, and Rich (2007) suggest that the management and dissemination of geographic information has developed through three distinct phases. The first phase was a decentralized and disorganized historical phase characterized by geographic information that was created for a single purpose and not distributed to the general public. The late eighteenth century ushered in an enlightened phase, characterized by global powers recognizing the value (primarily related to warfare) of mapping the Earth's surface and organizing that information in a centralized federal repository. Collecting and organizing geospatial information from the period spanning from the late nineteenth century through most of the twentieth century was labor intensive and expensive (National Research Council 
2004). This limited the large-scale production, curation, and dissemination of geospatial information to dedicated federal agencies such as the U.S. Geological Survey. The current or contemporary phase extends from late twentieth century through today and is marked by a rapid reduction in the costs associated with producing geographic information brought about by advances in, and the adoption of, information and communication technology.

The Goodchild et al. (2007) three-phase historical framework suggests that the development of geospatial information management and sharing has progressed uniformly. However, it is unfortunately clear that many, if not most, federal agencies remain locked into beliefs associated with the enlightened phase, in which geospatial information is only collected, stored and delivered for agency- or even program-specific needs. Consequently, many federal agencies are struggling with the need to transition toward a distributed and more collaborative system of data management while simultaneously meeting their congressionally mandated responsibilities (National Research Council 2001; National Research Council 1999). Agencies often fail to effectively manage and share geospatial data and services for a variety of reasons. Contributing factors include the complex and interdependent nature of federal agencies (Clarke and McCool 1996), limited labor pools and operating budgets that can be dedicated to geospatial information systems (Fogler 2011), and growing concerns over data security (National Research Council 2013). Federal agencies could benefit from tools and workflows allowing them to manage and deliver geospatial data effectively and efficiently in light of these barriers. The geospatial needs-assessment process presented here can serve as a critical tool, allowing agency personnel to provide public services in the most effective and efficient manner possible.

\section{The Needs-Assessment Process}

Needs assessments are systematic methods for determining and addressing discrepancies between current conditions and processes and desired conditions and processes (Altschuld and Kumar 2010). Needs assessments can be either extensive, wherein an analyst evaluates data across a large number of cases to determine generalizable needs, or intensive, in which critical needs are identified from an in-depth examination of a small number of cases (Kaufman, Rojas, and Mayer 1993). The needs-assessment process developed and presented here is intensive; intended to be applied to individual federal agencies or even programs/branches within those agencies. Following best practice guidelines for needs-assessment development (Leigh et al. 2000; Watkins, Meiers, and Visser 2012), our geospatial needs assessment is designed to

1. Bring together individuals who have an interest in, and influence over, the outcome of a particular decision 


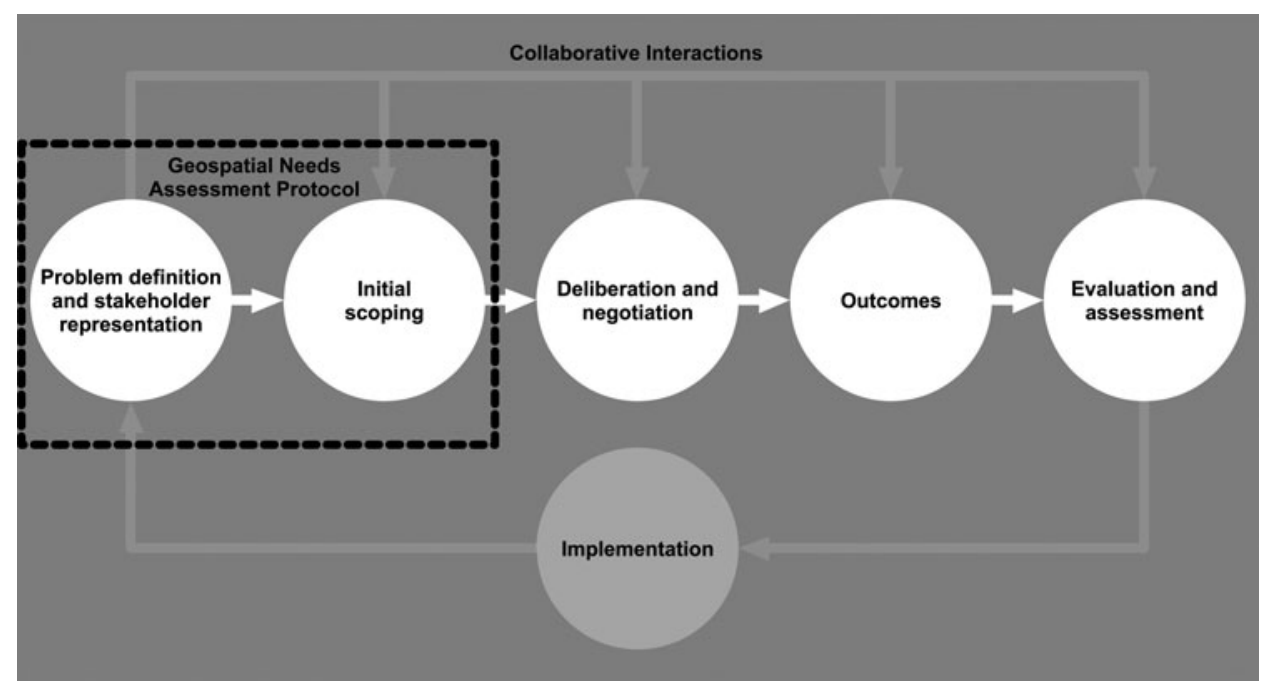

FIGURE 1 The needs assessment process is intended to be implemented as a first step to designing, or redesigning, a geospatial data management system.

2. Efficiently guide them through a process focused on identifying gaps between current processes/outcomes and desirable future processes/outcomes

3. Facilitate the collaborative identification and exploration of possible solutions.

The needs-assessment process is intended to be implemented as a first step to designing, or redesigning, a geospatial data management system (Figure 1). The process involves two specific phases, a problem definition and stakeholder representation phase and an initial scoping phase. The problem definition and stakeholder representation phase involves identifying key domain experts, end users, and geomatics or technical professionals committed to provide input throughout system design, development, implementation, and evaluation. The initial scoping phase involves a series of questions to be asked by the domain and geomatics experts of individual federal agency program representatives (the end users).

Problem Definition and Stakeholder Representation: Collaborative and Iterative Dialog between Application Domain Experts, End Users, and Geomatics Experts

The initial stage of the needs-assessment process involves identifying key individuals needed to both clearly identify the intended functionality of the soon-to-be developed geodatabase and determine what hardware, software, 
personnel, and system infrastructure is required to ensure those functional needs can be met. Recent research within the field of requirements engineering suggests that having representation from application domain experts (e.g., geology, forestry, urban planning), end users (in our case, federal agency representatives), and geomatics experts is imperative to the success and long-term adoption of the system (Grira, Bédard, and Sboui 2012).

Typically, in the design of a GIS system architects assume that the needs of end users can be exhaustively collected from domain experts alone (Grira, Bédard, and Roche 2009). This is especially true within federal agencies where one individual is often tasked with being the domain expert and the geomatics expert. This can make it difficult to both clearly articulate end users' high-priority analytical needs and also understand how emerging GIS tools and technologies can be leveraged to meet those needs.

Research on the successful design of nonspatial databases has repeatedly demonstrated that having expert input from the topical domain of interest as well as the information technology field leads to more user-friendly, interoperable, and widely adopted systems (Endsley and Jones 2011; Sutcliffe 2002). This research has yielded some explicit guidance on both identifying potential stakeholders who will be involved throughout the system's design and development (Sharp, Finkelstein, and Galal 1999) and how to best collect information regarding their needs (Aoyama 2005). Grira and colleagues (2012) have applied this guidance to geospatial systems, reiterating the need for a clear and unambiguous understanding of user roles in GIS design (Figure 2).

Application domain experts must have a clear understanding of the state of the science in their domain and be able to clearly articulate how existing tools used to advance that body of knowledge (e.g., modeling frameworks,

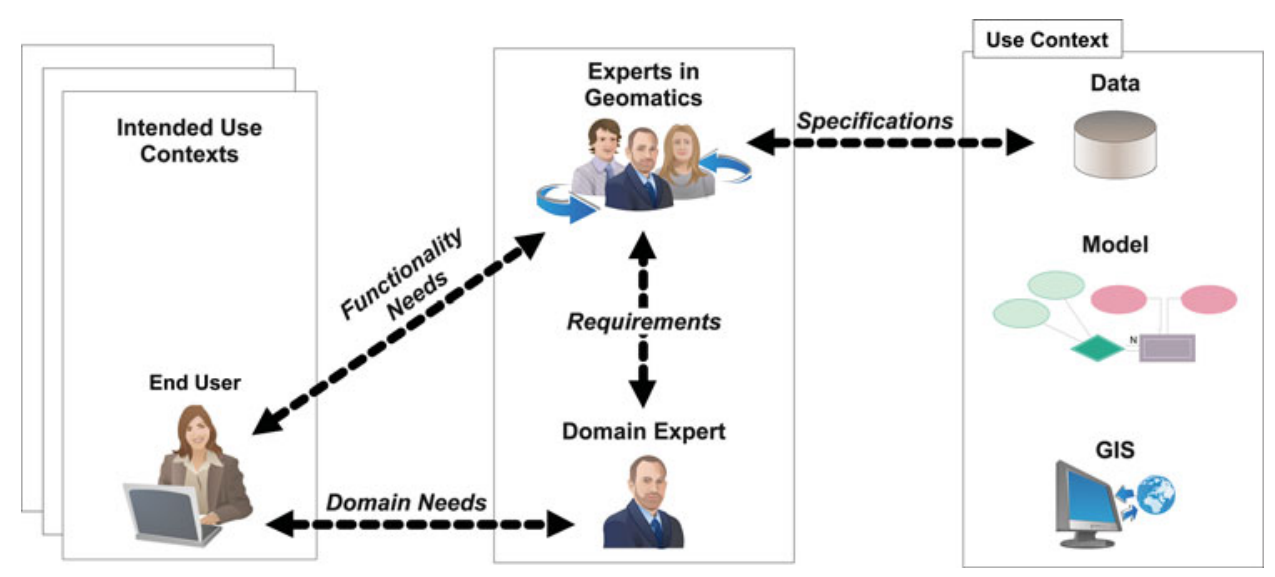

FIGURE 2 User-centered geospatial information system designs require input and coordination among application domain experts, end-users and geomatics experts (Grira, Bédard, and Sboui 2012). 
specific models) might affect the scientific and policy contexts in which the end user operates. For example, within the domain of recreation resource management, an application domain expert would be able to provide information and knowledge about how projections derived from downscaled climate models are being used to forecast shifts in visitation to specific recreation sites (Bitsura-Meszaros et al. in press). This knowledge, when conveyed to both the end user (a federal agency representative in this case) and GIS experts, could highlight novel and unexpected analytical tasks that may need to be performed by the agency to meet their federal, state or local mandates.

End users, such as federal agency personnel, provide detailed institutional knowledge of the economic and political contexts in which their organization operates. End users likely have numerous needs that could be facilitated through the development or refinement of a GIS. The prioritization of these needs is not always driven by statutory regulations and mandates as might be expected. Often, relatively short-term political factors affect how and where federal agencies' leadership choose to spend their limited stocks of human and financial capital (Costanza 1991).

Geomatics experts provide the technical knowledge needed to transform end users' needs into outcomes that can be produced by the GIS. Geomatics experts are able to provide a clear understanding of how the types of geospatial data to be represented within the GIS will affect subsequent analytical options. For example, some geospatial data managed by federal agencies refer to specific federally funded projects that may or may not have an explicit geospatial location. A prime example is federal grants that, although awarded to a specific institution or organization such as a university, the activities they enable are likely to occur somewhere else such as a field site. Consequently, geospatial data tied to the project can be represented as a point placed at the funded organization or institution or as another type of spatial representation (line or polygon) demarking where the activities funded by the project will actually occur. The decision of which spatial representation to use will have a direct impact on what types of analyses an end user can perform on those data. It is the role of the geomatics expert to communicate with end users, listen to them express how they would like to use their data and then clearly describe how decisions related to those data's topological representations would affect their attributes and the viability of subsequent analytical processes.

Initial Scoping: Questions to Elicit Geodatabase Needs and Management Capacities

To facilitate the dialog between domain experts, federal agency end users, and geomatics experts, we have developed a series of scoping questions to 
be asked by the geomatics and application domain experts of federal agency end users. The questions are to be completed by at least one program lead (e.g., a manager) and at least one technical user (e.g., a staff scientist or GIS technician). The scoping questions (Table 1) are organized into four sets, each of which serves a distinct purpose. The four-question sets include identification of

1. program purpose and general activities

2. program-related geospatial questions and data

3. existing database organization and design

4. database and Web-mapping application maintenance capabilities.

\section{Question Set 1-Identification of Program Purpose and General Activities}

This initial question set is intended to give the domain and geomatics experts a better understanding of the federal agencies' statutory responsibilities, organizational structure, and the general day-to-day operations of agency personnel. The technical and domain experts should have a basic understanding of the agency's purpose, mission, and objectives through a detailed review of available secondary material. Agency Web sites, brochures, and publications are valuable pieces of information that can provide the domain and geomatics experts with a basic understanding of the agency and its operations. Subsequent informal discussions with agency personnel are also highly recommended because they can provide more detail on agency operations and mandates. More importantly, these initial discussions often yield insight into how current political climates can, or are likely to, shape the agency's immediate geospatial information needs. Often, agencies' congressional mandates exceed the activities and outcomes that can be generated from appropriated dollars, leaving discretionary decisions up to current leadership (Olson 1995). Opening up these initial lines of communication are essential precursors to soliciting meaningful and interpretable responses from the scoping questions.

\section{Question Set 2-Identification of Program-Related Geospatial Questions and Data}

The second question set identifies the scope of agency activities that involve, or could involve, geospatial data. The key questions used to generate these responses are Q2.1, "What geospatial questions does your program currently address with your existing data?" and Q2.3, "What geospatial questions would your program like to address?" These are open ended and agency 
TABLE 1 Geospatial Needs Assessment Scoping Questions

Question set 1 - Identification of program purpose and general activities:

Q1.1 - What is the primary purpose of your program?

Q1.2 - What commonly asked or requested tasks does your program perform (or are asked to perform)?

Q1.3 - If you could take one repeatable task off of your plate, what would it be?

Question set 2 - Identification of program-related geospatial questions and data:

Current program-related geospatial questions and data:

Q2.1 - What geospatial questions does your program currently address with your existing data? Please provide as many specific examples as you can think of and also provide a description of why each question is being addressed.

Q2.2 - List all of the data layers needed to address those questions:

Data layer description:

Data layer representation (point, line or polygon):

Data layer source:

Is this data layer essential?

Is this data restricted?

Are there alternate, comparable data sources available?

Other notes:

Future program-related geospatial questions and data:

Q2.3 - What geospatial questions would your program like to address? Please provide as many specific examples as you can think of and also provide a description of why each question should be addressed.

Q2.4 - What data layers would help your program address those questions?

Data layer description:

Data layer representation (point, line or polygon):

Data layer source:

Is this data layer essential?

Is this data restricted?

Are there alternate, comparable data sources available?

Other notes:

Q2.5 - How does your program currently, or would it like to, interact with geospatial data? (Select one of the options from the list below or provide your own answer following the 'Other' option)

a) We perform queries or searches based on user input

b) We dynamically edit tabular and attribute data

c) We upload supporting information (e.g., pictures, monitoring data, reports, etc.) to the database

d) Other:

Q2.6 - Who are the end users of your program's data, reports or products? (Select all that apply from the list below or provide your own answer following the 'Other' option)

a) Internal agency personnel

b) Other agencies. Please list the agencies:

c) The general public

d) Elected officials

e) Other:

Q2.7 - How does your program currently, or would it like to, visualize program-specific geospatial database query results? (Select all that apply from the list below or provide your own answer following the 'Other' option)

a) We view results on a personal, non-web-enabled, GIS

b) We view results via a web-based mapping application

c) We view and results on printed text reports

d) We publish results on a personal, non-web-enabled, GIS

e) We publish results to a web-based mapping application

(Continued on next page) 
TABLE 1 Geospatial Needs Assessment Scoping Questions (Continued)

f) We have a need to export results in a certain file format (e.g., Microsoft Excel spreadsheets, shapefiles, html webpages, etc.). If so, please describe:

g) Other

Question set 3 - Identification of existing database organization and design:

Q3.1 - How are geospatial data currently stored within your program?

Q3.2 - Where are these data physically located? (Select one of the options from the list below)

a) Data are centrally located. If so, please describe where:

b) Data are located at remote locations. If so, please describe where:

Q3.3 - How often is the geospatial data currently managed by your program updated, if at all?

Q3.4 - Is your program's geospatial and/or tabular data managed in a relational database structure (i.e., data records are stored in independent tables, but are linked through common key fields such as ID numbers)? If so, please provide a description of how individual data tables are related to one another).

Question set 4 - Identification of database and web-mapping application maintenance capabilities:

Q4.1 - For each of the following categories, describe what geospatial information capabilities your program currently has?

Personnel:

Hardware:

Software:

Other (please describe):

Q4.2 - Are any of those GIS capabilities currently shared? If so, please list the other organizations with which your program shares capabilities and describe the relationship.

Q4.3 - Describe how your program's geospatial information capacities are likely to change in the next two to three years:

representatives should be encouraged to provide as many specific responses as possible and to provide a description of why they listed those questions. Asking for a description of why each question is, or should be, addressed provides additional insight into current agency activities and future needs that can be valuable in the subsequent stages of system development.

The second question set also solicits information about specific spatial and tabular data used by the agency. For each data layer or table, agency personnel are prompted to provide additional information regarding data representation (point, line or polygon), source and importance relative to the agency's geospatial analytical needs. Agency representatives, especially if they are not familiar with GIS, will not be able to provide all this information for each piece of data. A complete reporting of all data used by the agency is not essential, although more information can be gathered from more complete lists. The intent is to give the geomatics expert a better understanding of what types of data will most likely be integrated into the geodatabase. Additionally, having information on data currently used, or likely to be used, by the agency allows domain experts to identify opportunities for reducing data redundancies by tapping into authoritative geoportals managed through interagency initiatives (Maguire and Longley 2005). 
Question set 2 also includes two questions, Q2.5 and Q2.6, designed to provide a better understanding of how data are managed within the agency and distributed to their constituents. Most large federal agencies have both internal and external GIS needs, internal needs being the functionality required by agency personnel themselves and external needs being the functionality required by the agency's constituents (typically the general public). Answers to questions Q2.5 and Q2.6 provide an opportunity for the domain and geomatics experts to better understand the balance between these two distinct types of needs; this will subsequently inform decisions about system architecture.

Question Set 3-Identification of Existing Database Organization and Design

The purpose of the third question set is to catalog the geospatial information already being used within the agency and to determine how that information is currently being stored. These questions clarify the technological abilities and normative operating patterns already in place, and also lay the groundwork for rooting out either redundant or underutilized organizational resources. This question set also facilitates the location of any existing geodatabases. Answers to these question are critical to discovering agency representatives who possess important information regarding the location of existing data. Locating data is not always straightforward in federal agencies with high levels of turnover and horizontal shifting of technical personnel. Although strictly technical on the surface, answers to these questions can also lead to a better understanding of the qualitative characteristics (e.g., political, economic) influencing agency personnel's capacity to manage and maintain their geospatial information and infrastructure.

\section{Question Set 4 - Identification of Database and Web-Mapping Application Maintenance Capabilities}

The fourth question set solicits feedback with the goal of generating a taxonomy of geodatabase and Web-mapping application maintenance capabilities (Bai, Di, and Wei 2009). For instance, Q4.1 extends the information generated from question set 3 by going beyond describing geospatial data caches to cataloging personnel, hardware, and software capacities. The distinction is significant in that the solicitation now concerns all aspects of an analytical work flow, therefore generating a nearly complete description of the geospatial data management system's operational hierarchy. Relatedly, Q4.2 brings to light any agencies that might benefit from inclusion into the needs-assessment process. In this sense, the geospatial needs assessment can 
serve as an opportunity to foster communication between disparate agencies (Goodchild, Fu, and Rich 2007).

Q4.3 is significant because it provides insight into how agency leadership envisions their geospatial data management capacities and needs changing in the future. Inquiring about anticipated geospatial data needs and management capacities can provide valuable insight affecting system design decisions.

Application of the Needs-Assessment Process: The National Park Service Conservation and Outdoor Recreation Branch Programs

The needs-assessment process was designed to identify individuals involved in the development of a federal geospatial data management system, allow them to point out gaps between current and desired processes, and explore possible solutions. To demonstrate its utility, we present a case-study application to programs within the NPS Conservation and Outdoor Recreation (COR) Branch.

\section{The National Park Service Conservation and Outdoor Recreation Branch}

The NPS COR Branch was initially conceived as a vehicle to redistribute select NPS funds and assets (National Park Service 2015). The COR Branch seeks to broaden the scope of the NPS via mission-specific and environmentally diverse funding disbursements. Collectively, the COR Branch is comprised of nine unique programs described in Table 2 (National Park Service 2015).

\section{Application}

The initial stage of the process involves identifying key individuals needed to both clearly describe the intended functionality of the soon-to-be developed database and determine what hardware, software, personnel, and system infrastructure is required to ensure that those functional needs can be met. We initiated our application of the needs-assessment process to the COR Branch by convening a series of initial meetings involving COR Branch program leadership, GIS technical support personnel, and our team members, which included a domain expert (a faculty member whose research focuses on natural resource management issues) and two geomatics experts. Our team members met with representatives from each of the COR Branch programs individually. The initial meetings were largely unstructured, with open dialog and communication focused on each COR Branch program's organizational structure, its purpose and its current and desired use of geospatial 
TABLE 2 Programs of the National Park Service Conservation and Outdoor Recreation Branch

\begin{tabular}{|c|c|}
\hline Program & Description \\
\hline State and Local Assistance & $\begin{array}{l}\text { Helps communities create new parks and recreation areas by } \\
\text { transferring federal land to state and local governments. }\end{array}$ \\
\hline $\begin{array}{l}\text { Hydropower Recreation } \\
\text { Assistance }\end{array}$ & $\begin{array}{l}\text { Provides technical assistance on hydropower licensing and } \\
\text { makes recommendations about recreation access and } \\
\text { facilities, instream flow rates and riparian corridor and } \\
\text { conservation buffer zones. }\end{array}$ \\
\hline National Rivers Inventory & $\begin{array}{l}\text { Listing of national free-flowing river segments believed to } \\
\text { possess cultural value and be of more than regional } \\
\text { significance. }\end{array}$ \\
\hline $\begin{array}{l}\text { National Rivers Recreation } \\
\text { Database }\end{array}$ & $\begin{array}{l}\text { Database managed by the COR Branch providing river } \\
\text { recreation and management information useful to resource } \\
\text { managers and interested publics. }\end{array}$ \\
\hline National Trails System & $\begin{array}{l}\text { Provides for outdoor recreation needs, and promotes the } \\
\text { enjoyment, appreciation and preservation of open-air, } \\
\text { outdoor areas and historic resources. }\end{array}$ \\
\hline National Water Trails System & $\begin{array}{l}\text { National network of water trails designated for management, } \\
\text { protection and increased recreational access. }\end{array}$ \\
\hline $\begin{array}{l}\text { Partnership Wild and Scenic } \\
\text { Rivers }\end{array}$ & $\begin{array}{l}\text { Preserves - in free-flowing condition-selected rivers that } \\
\text { possess outstandingly remarkable scenic, recreational, } \\
\text { geologic, historic or fish and wildlife value. }\end{array}$ \\
\hline $\begin{array}{l}\text { Rivers, Trails, and } \\
\text { Conservation Assistance }\end{array}$ & $\begin{array}{l}\text { Supports community-led natural resource conservation and } \\
\text { outdoor recreation projects such as conserving and } \\
\text { improving access to rivers. }\end{array}$ \\
\hline $\begin{array}{l}\text { Rivers, Trails, and } \\
\text { Conservation Assistance - } \\
\text { Communications }\end{array}$ & $\begin{array}{l}\text { Strategic tool leveraged across COR Branch programs to } \\
\text { distribute information efficiently and effectively between } \\
\text { agency personnel. }\end{array}$ \\
\hline
\end{tabular}

data. The informal nature of the meetings, which ranged in duration from forty-five minutes to one and one-half hours, allowed for extended and freeflowing discussion. The information gleaned through these initial meetings, collected via liberal note taking and post-meeting debriefings, was essential to interpreting the responses provided by agency personnel to the follow-up scoping questions.

The scoping questions (Table 1) were provided to program representatives via e-mail shortly after the series of initial unstructured meetings. Representatives were given two weeks to provide their answers to the scoping questions. However, most responses were provided within several days given the personal connections established during the previous introductory meetings. Responses were compiled, read, interpreted, and used to generate a list of desirable geospatial information system functionalities and needs. These needs, which were specific to each COR Branch program, were subsequently compiled into a program-specific, geospatial-needs matrix (Table 3). Constructing the program-specific needs matrix facilitated the identification of a common set of critical needs across the nine different programs.

This collective needs matrix confirmed the assumptions generated during our initial scoping meetings with COR Branch program leadership. Specif- 


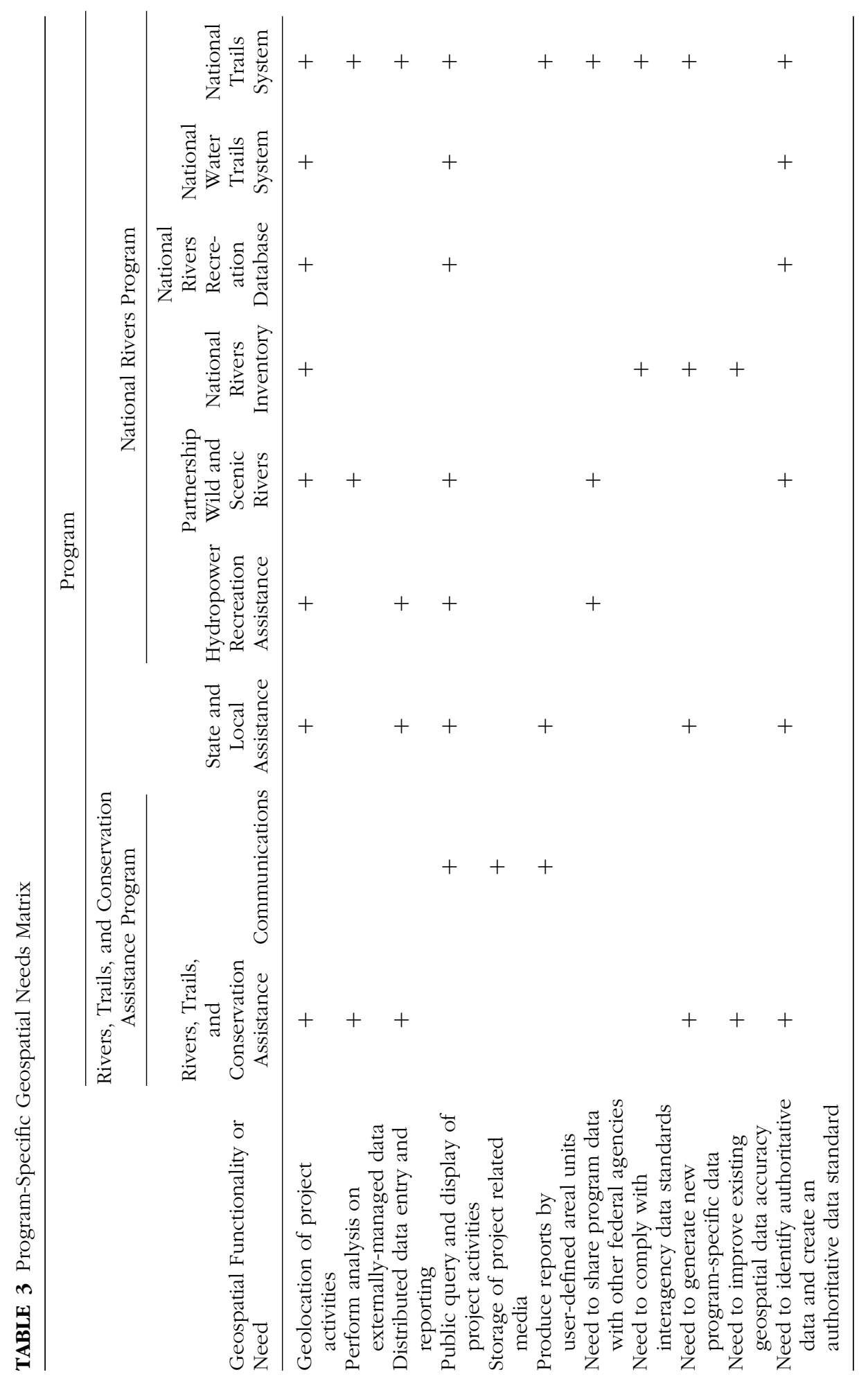


TABLE 4 Critical and Desirable Geospatial Needs Across the COR Branch Programs

Critical Needs
1. The development of an enterprise geospatial database (a centrally located and accessible
multi-user database platform).
2. The identification and maintenance of authoritative spatial and tabular data.
3. The hiring of a dedicated geospatial database and program coordinator.
4. The ability to build custom public and internal web-based services and applications that
support program-specific needs.

ically, the collective needs matrix identified four critical needs for the entire COR Branch (Table 4). The critical agency-wide needs identified were to

1. develop an enterprise geodatabase (a centrally located and accessible multiuser spatial and tabular database platform)

2. identify and maintain authoritative spatial and tabular data

3. hire a dedicated geodatabase and program coordinator

4. build custom public and internal Web-based services and applications that support program-specific needs.

The first critical need identified was to develop a centralized geodatabase. An enterprise infrastructure would allow the COR Branch to centrally store, manage, and disseminate geospatial and nonspatial data. The centralized infrastructure would also provide the ability to deliver Web-based services and applications developed and managed by external agencies and partners using common, ideally authoritative, data. It was not surprising that the need for a centralized geodatabase topped the COR Branch's critical needs list. The needs-assessment process allowed us to elucidate the general need for an enterprise (i.e., multiuser) database and associated infrastructure. The need for an enterprise geodatabase became clear by contrasting responses we received from agency representatives who worked in the Washington, D.C. offices with the responses received from regional representatives located throughout the country.

Washington personnel conveyed a strong desire for the geospatial data management system to have the ability to track program efforts (e.g., grant dollars administered, projects completed) across the nation and generate reports for common user-defined areal units such as states or congressional districts. However, regional personnel expressed less of a need for the system to be used as a reporting tool (which directly impacts subsequent years' congressional appropriations) and a much greater desire to simply search and query the database to answer relatively simple, yet important, questions such as "To which cities within my region should I distribute Rivers, Trails, and Conservation Assistance funds if I want to maximize those funds' ability to aid urban, minority youth?" This divergence highlights how the functional 
needs placed upon a geospatial data management system are highly variable within federal agencies. The specific needs of agency personnel are implicit and directly tied to their role within the organization, which can lead to divergent, or potentially conflicting, needs going unnoticed. For the COR Branch, it was only by asking the questions in our needs-assessment process that internal discrepancies became explicitly stated and shared (see Table 4).

The second critical need involved identifying and developing authoritative datasets, which would reduce data duplication and increase the ability of COR Branch program personnel and Washington and regional/local/unit offices to collaborate using common data and information. The third critical need was to establish a dedicated geodatabase and program coordinator. Currently the COR Branch personnel do not have the requisite skills or abilities to establish or maintain a centralized COR Branch-specific geospatial platform. A full-time personnel position would ensure continued long-term support for the COR Branch's mapping needs; the position would also provide continuity as those needs continue to evolve. The fourth and final critical need was to utilize internal- and external-facing Web-based services and applications that support program-specific decisions. Currently, many of the COR Branch's programs make spatially dependent decisions, such as deciding which community assistance projects receive funding, without relevant geospatial data. For the COR Branch, we suggested that the use of custom Web-based services and applications would facilitate more consistent, objective and defensible decisions.

The agencywide critical needs were subsequently used as pivotal decision criteria in determining what type of geospatial data management system was appropriate to develop for the agency. For example, knowing many programs within the COR Branch could benefit from the development of an enterprise geodatabase, our next question became "What are the characteristics of an enterprise geodatabase (e.g., open-source or commercial, publically facing or internal access only) that would best enable the COR Branch and its programs to meet their congressionally mandated goals in the most cost-effective manner. Figure 3 illustrates how the identification of agencywide critical needs were used to generate additional questions aiding geodatabase system design decisions.

Based on the geospatial needs assessment conducted with COR Branch program representatives within both the Washington and regional offices, we identified and developed a set of potential geospatial database development scenarios for addressing the geospatial needs of COR Branch programs. More detail on these scenarios can be found in Smith et al. (2014). We presented the scenarios to the COR Branch leadership in deliberative discussions with constructive dialog leading to the selection of a specific scenario to be pursued by the agency in the immediate future. What is important to emphasize is how the information generated through the needs-assessment process enabled collaborative discussion between agency personnel and the geo- 
CRITICAL NEEDS

The development of an enterprise geodatabase $=$

What are the characteristics of an enterprise geodatabase (e.g., open-source or commercial,

publically-facing or internal access only, etc.) that would best enable the agency and its

programs to meet their congressionally mandated goals in the most cost-effective manner?

The identification and maintenance of authoritative spatial and tabular data

What data standards exist that are both applicable to the topical domain of the National Park

Service's Conservation and Outdoor Recreation Branch programs and are endorsed by the

Federal Geographic Data Committee? How easily could these standards be adopted?

The hiring of a dedicated geospatial database and program coordinator =

What are the requisite knowledge, skills and abilities that would be needed within a

geospatial database and program coordinator to meet the current and likely future needs

of the National Park Service's Conservation and Outdoor Recreation Branch Programs?

The ability to build custom public and internal web-based services

and applications that support program-specific needs

What are the main functions that will be performed by end-users of the web-based

service? Will the service be used just for standard query and display purposes, or is

dynamic reporting a need as well? Will external data sources need to be displayed?

FIGURE 3 The identification of agency-wide critical needs were used to generate additional questions aiding geodatabase system design decisions.

database design team: discussion that facilitated making the most informed decision possible regarding how geospatial data are to be managed.

\section{CONCLUSIONS}

Federal agencies face a broad set of challenges when attempting to design geospatial data management systems. These challenges stem from the complex and interdependent nature of agency mandates and rising concerns over data validity and security (National Research Council 2013; National Research Council 2001). Additionally, federal agencies often have limited pools of human and financial resources to dedicate to developing geospatial data management systems (Fogler 2011). Frequently, geospatial data are managed in-house by individual GIS technicians; this makes it extremely difficult to ensure the interoperability of geospatial information across disparate programs, let alone disparate agencies (Goodchild et al. 1999). Over the past several decades, interagency initiatives have attempted to eliminate redundancy and implement standards to procure, store, and deliver geospatial data (National Research Council 1993; National Research Council 1999). These initiatives however, have yet to be widely adopted (Joshi and Joshi 2013). Until most federal geospatial data management systems are interoperable, federal agencies could benefit from the development of tools and workflows enabling them to manage and deliver geospatial data in the most efficient manner possible.

In this paper, we have presented a two-phase geospatial needsassessment process. The process adds to previous scholarship focused on designing and developing effective geospatial information systems (Grira, 
Bédard, and Sboui 2012) by providing focused guidance targeted at federal agencies. Specifically, the problem definition and stakeholder representation phase of the process provides guidance on how domain scientists, federal agency representatives, and geomatics experts can come together and engage in collaborative discussions focused on an agency's immediate and future geospatial data needs and how those needs might be affected by external shifts in context (e.g., changes in information technology systems, political and economic forces, and scientific knowledge within the domain area). The initial scoping phase of the process involves a series of questions to be asked by the domain and geomatics experts of individual federal agency program representatives. Each of these questions has a specific purpose. Collectively, the scoping questions provide vital information needed to

1. prioritize agencies' geospatial information needs

2. identify agencies' capacity to manage a centralized geodatabase

3. determine agencies' capacity to deliver Web-mapping services to the public

4. identify barriers that limit agencies' ability to design and manage a geospatial data management system.

We also presented a case-study application of the process to programs within the NPS COR Branch. This branch serves as an ideal testbed for the process, given that it is composed of nine different programs, each of which has distinct congressional mandates, programmatic needs, clienteles, cooperating agencies, and types of spatial and tabular data. Throughout the case-study application, we highlighted how the needs-assessment process enabled our project team, along with agency leadership, to make critical decisions regarding the design of a new interoperable GIS that would meet the current and future needs of the agency.

While the process can be implemented as a standalone tool, most federal agencies willing to engage in a geospatial needs-assessment process are usually ready to develop or refine a geospatial data management system based on the recommendations made by the domain and geomatics experts and the collaborative discussions that follow. Whether implemented as a stand-alone tool or as part of a larger geospatial information system design and development framework, the needs-assessment process provides a comprehensive and logical work flow for system developers and administrators to use as they create or refine geospatial data management systems.

\section{REFERENCES}

Altschuld, J. W., and D. D. Kumar. 2010. Needs Assessment: An Overview. Thousand Oaks, CA: Sage. 
Aoyama, M. 2005. Persona-and-scenario based requirements engineering for software embedded in digital consumer products. In: Proceedings of the IEEE Integrated Requirements Engineering Conference, Paris, France, 85-94.

Bai, Y., L. Di, and Y. Wei. 2009. A taxonomy of geospatial services for global service discovery and interoperability. Computers \& Geosciences, Geoscience Knowledge Representation in Cyberinfrastructure, 35(4): 783-790. doi:10.1016/j.cageo.2007.12.018

Bitsura-Meszaros, K., et al In press. Examining tourism destination risk and community adaptive capacity along the north shore of Lake Superior. Michigan Journal of Sustainability, 3, 111-119.

Clarke, J. N., and D. C. McCool. 1996. Staking Out the Terrain: Power and Performance among Natural Resource Agencies. 2nd ed. Albany, NY: State University of New York Press.

Costanza, R. 1991. Assuring sustainability of ecological economic systems. In: Ecological Economics: The Science and Management of Sustainability, R. Costanza, (Ed.), 331-343. New York: Columbia University Press.

Endsley, M. R., and D. G. Jones. 2011. Designing for Situation Awareness: An Approach to User-Centered Design (2nd ed.). Boca Raton, FL: CRC Press.

Fogler, P. 2011. Issues and Challenges for Federal Geospatial Information. Congressional Research Service Report 7-5700. Washington, DC: Congressional Research Service.

Goodchild, M. F., et al, eds. 1999. Interoperating Geographic Information Systems. Boston: Kluwer Academic.

Goodchild, M. F., P. Fu, and P. Rich. 2007. Sharing geographic information: An assessment of the geospatial one-stop. Annals of the Association of American Geographers 97(2): 250-266.

Grira, J., Y. Bédard, and S. Roche. 2009. Spatial data uncertainty in the VGI world: Going from consumer to producer. Geomatica: Journal of the Canadian Institute of Geomatics 64(1): 61-71.

Grira, J., Y. Bédard, and T. Sboui. 2012. A collaborative user-centered approach to fine-tune geospatial database design. In: Advances in Conceptual Modeling, S. Castano, P. Vassiliadis, L. V. S. Lakshmanan, and M. L. Lee (Eds.), 272-283. ER 2012 Workshops: CMS, ECDM-NoCoDA, MoDIC MORE-BI, RIGiM, SeCoGIS, WISM, LNCS 7518. Heidelberg: Springer.

Joshi, P. K., and A. Joshi. 2013. Certification of geospatial data. Current Science 105(6): 759.

Kaufman, R., A. M. Rojas, and H. Mayer. 1993. Needs Assessment: A User's Guide. Englewood Cliffs, NJ: Educational Technology Publications.

Leigh, D., et al 2000. Alternate models of needs assessment: Selecting the right one for your organization Human Development Quarterly, 11(1): 87-93.

Maguire, D. J., and P. A. Longley. 2005. The emergence of geoportals and their role in spatial data infrastructures. Computers, Environment and Urban Systems, Geoportals, 29 (1): 3-14. doi:10.1016/j.compenvurbsys.2004.05.012

National Park Service. 2015. National Center for Recreation \& Conservation National Center for Recreation \& Conservation. January 8. http://www.nps.gov/ncrc/index.htm

National Research Council. 1993. Toward a Coordinated Spatial Data Infrastructure for the Nation. Washington, DC: National Academies Press. 
1999. Distributed Geolibraries: Spatial Information Resources. Washington, DC: National Academies Press.

- 2001. National Spatial Data Infrastructure Partnership Programs: Rethinking the Focus. Washington, DC: National Academies Press.

- 2004. Licensing Geographic Data and Services. Washington, DC: National Academies Press.

. 2013. Future U.S. Workforce for Geospatial Intelligence. Washington, DC: National Academies Press.

Olson, M. K. 1995. Regulatory agency discretion among competing industries: Inside the FDA. Journal of Law, Economics, E Organization, 11(2): 379-405.

Sharp, H., A. Finkelstein, and G. Galal. 1999. Stakeholder identification in the requirements engineering process. In: Proceedings of the IEEE Integrated Requirements Engineering Conference, 387-391. Limerick, Ireland.

Smith, J. W., B. Slocumb, and C. T. Smith. 2014. Needs Assessment and Guidance to Define a Clear Vision for a Geospatial Mapping System to Service the Needs and Opportunities of the National Park Service Conservation and Outdoor Recreation Branch and Related Programs. Raleigh, NC: NC State University, College of Natural Resources, Center for Geospatial Analytics.

Sutcliffe, A. 2002. User-Centered Requirements Engineering: Theory and Practice. London: Springer-Verlag.

Watkins, R., M. W. Meiers, and Y. Visser. 2012. A Guide to Assessing Needs: Essential Tools for Collecting Information, Making Decisions, and Achieving Development Results. Washington, DC: World Bank.

Wood, D., and J. Fels. 1992. The Power of Maps. New York: Guilford. 